\title{
Conjuntos de acción y grupos motores para la transformación ambiental ${ }^{1}$
}

\author{
Tomás R. VILLASANTE \\ Universidad Complutense \\ tvillasante@cps.ucm.es
}

Recibido: 13-05-2014

Aceptado: 08-05-2015

\section{Resumen}

En primer lugar, se presenta un esquema sobre como la "dominación financiera mundial" controla tanto los mercados de producción como las políticas públicas. A esta "pirámide" se oponen movimientos sociales que surgen como "manglares" de las bases pro-comunes y en la defensa de los ecosistemas. En segundo lugar, se analizan las dinámicas de estos movimientos desde sus fondos eco-sociales, como pueden eco-relacionarse a partir de "mapeos de actores", con estrategias de "conjuntos de acción". Se repasan las preguntas emergentes de algunos de estos "conjuntos de acción" actuales. En tercer lugar, se presentan los "grupos motores" como grupos de iniciativas que aparecen en muchos procesos y que significan un tipo de liderazgos colectivos y no tan patriarcales, y capaces de realizar metodologías participativas más que sectarismos ideológicos.

Palabras clave: financiarización, neo-liberalismo, bienes pro-comunes, ecosistemas, movimientos sociales, mapeo de actores, conjuntos de acción, grupos motores, liderazgos colectivos, metodologías participativas.

${ }^{1}$ Este artículo es parte de una investigación financiada por el Proyecto Prometeo (Gobierno del Ecuador) en acuerdo con el Programa Acordes de la Universidad de Cuenca. 


\title{
From the Eco-Social Base, Social Movements and Power Groups
}

\begin{abstract}
An outline of how the "global financial domination" controls both the production markets and the public policy is presented. In this "pyramid", the social movements that emerge as "mangroves" of the pro-common bases and defence ecosystem are opposed. Secondly, the dynamics of these movements are analysed from their eco-social funds, how they can be eco-linked from "stakeholder mapping" with strategies of "action sets". Emerging questions from some of these current "action sets" are reviewed. Thirdly, the "power groups" are presented as initiative groups that appear in many processes and represent a kind of collective leaderships and not as patriarchal, capable of performing and participatory methodologies more than ideological sectarianism.
\end{abstract}

Keywords: Financialization; Neo-liberalism; Pro-common Goods Ecosystems; Social Movements; Stakeholder Mapping; Action Sets; Power Groups; Collective Leaderships; Participatory Methodologies.

\section{Referencia normalizada}

Villasante, Tomás R. (2015): “Conjuntos de acción y grupos motores para la transformación ambiental”, Política y Sociedad, 52 (2), pp. 387-408.

Sumario: 1. Objetivos y metodología de partida. 2. La lucha desde los "manglares" o "conjuntos de acción". 3. Conjuntos de acción emergentes desde los fondos eco-sociales. 4. Grupos Motores hacen emerger procesos de creatividad social. 5. Resumiendo la estrategia implicativa ambiental 6. Bibliografía. 


\section{Objetivos y metodología de partida}

El debate del papel de los movimientos sociales en la actual coyuntura, de cara a una posible transformación social del sistema dominante, más o menos en transiciones cortas o largas, nos lleva a un análisis del contexto en que se mueven y a las nuevas prácticas e instrumentos que usan. Lo que aquí se presenta se basa en las experiencias de metodologías participativas que colectivamente hemos venido desarrollando en la red CIMAS. No se van a detallar aquí tales metodologías, sino simplemente señalarlas como punto de arranque, y sobre todo destacar algunas concepciones clave que ilustran unos enfoques innovadores sobre los movimientos sociales. El objetivo es avanzar en el debate sobre el papel de los movimientos sociales, o mejor aún los "conjuntos de acción" con sus "grupos motores" de cara a posible transiciones transformadoras del sistema dominante.

Desde hace un par de décadas en el Observatorio Internacional CIMAS (www. redcimas.org), venimos siguiendo unas metodologías contra las actuales relaciones de poder, a favor de des-construcciones y creatividades con la gente que se implica en el proceso. Una rueda tiene forma para avanzar, se puede ver de una vez (como un "mandala" oriental que integra los elementos), y permite la circulación de los laberintos a las espirales².

Se suele partir de un "analizador", un hecho de referencia que sea lo bastante importante para las personas y grupos que se quieren implicar en un proceso. Un suceso que sirve para que se ponga en marcha una rueda de pasos y saltos. Conviene que nos podamos poner de acuerdo, en sentido "a favor" de las agujas de un reloj, sobre los pasos a dar en la metodología. El "síntoma-analizador" en el habitar provoca un desorden local, un grito y/o "dolor/placer", por lo que algunos grupos se preocupan, autoreflexionan, y evalúan la situación. Pasan a construir mapeos de iniciativas, a potenciar, conversar y escuchar a la gente, los conjuntos de acción, y luego a des-construir con multi-lemas sus contradicciones internas y externas. En las devoluciones participativas se puede crear, profundizar y consensuar, una idea-fuerza integral e integradora. Desde ahí, a su vez, se pueden lanzar iniciativas operativas, que si se activan, trabajan y realizan con coherencia, se pueden producir los desbordes reversivos, que lleven a resultados instituyentes, democracias de iniciativas en el habitar. Vamos a destacar aquí la cuestión de los "conjuntos de acción" y de los "grupos motores".

${ }^{2}$ En la página web del CIMAS hay 6 DVD que van mostrando el proceso, hay un Manual de licencia libre, y en la Biblioteca varios artículos (y libros) para cada uno de los pasos o saltos que se proponen. 
Cuadro 1: Rueda-Mandala de la Sociopraxis

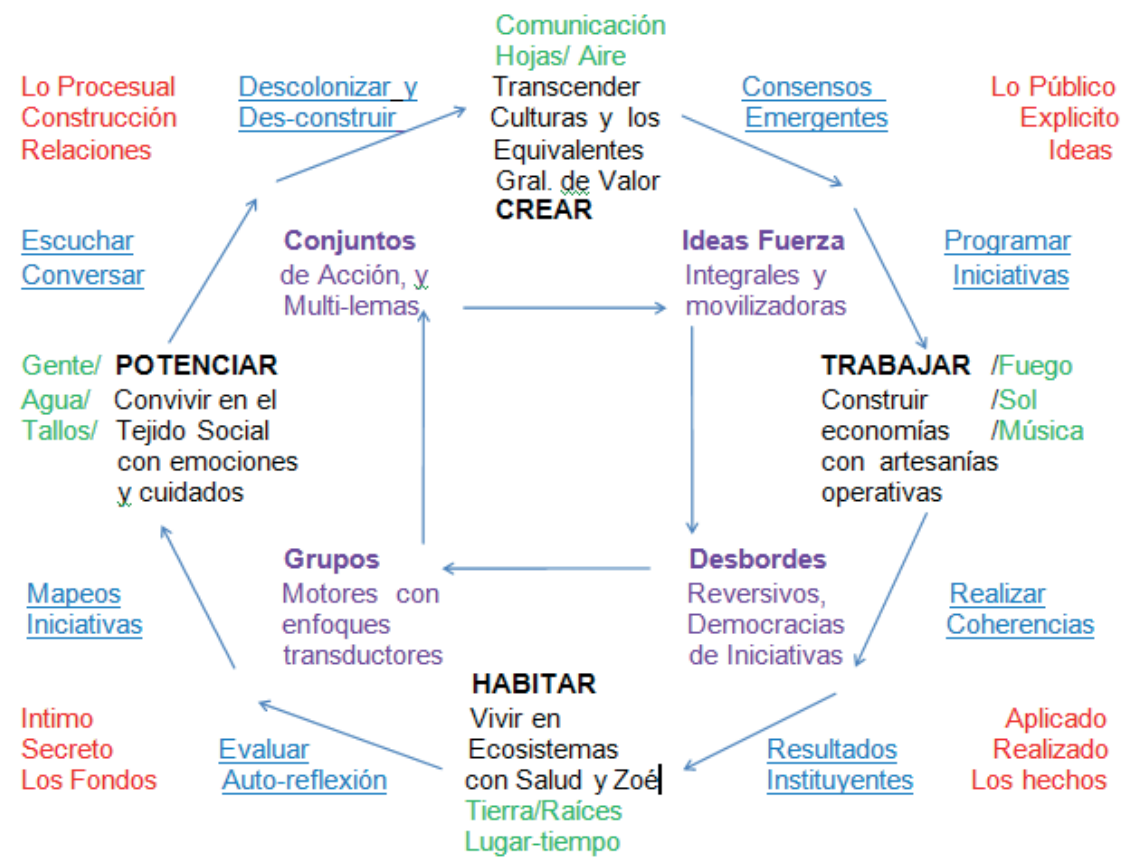

Fuente: Elaboración propia.

\section{La lucha desde los "manglares" o "conjuntos de acción"}

En la economía política las disputas ideológicas del eje entre izquierda-derecha se van viendo superadas por las luchas de los de abajo contra los de arriba (tanto en Europa como en América Latina, por ejemplo). Algunos autores que han representado gráficamente esto cruzan diversos ejes de contradicciones y nos pueden ayudar a situarnos en unos esquemas más complejos pero también más reales que los dominantes en el siglo pasado. Johan Galtung, por ejemplo, con sus pentalemas (1984) nos situaba entre el rojo del Estado y el azul del Mercado, pero por encima colocaba el amarillo de las economías del Pacífico (mucho Estado y mucho Mercado al mismo tiempo), y en la base colocaba el verde de los movimientos que pugnan por desbordar al Mercado y al Estado por abajo, que llamaríamos "otro mundo es posible" como el Foro Social Mundial desde los movimientos sociales.

Hazel Henderson (1989) había diseñado una tarta con varios pisos, donde el vértice glaseado representaba (arriba) las finanzas, luego venía el piso de la economía produc- 
tiva privada, más abajo la economía pública, más abajo la economía informal (ya poco visible), y lo más importante como base (más abajo aún) los intercambios domésticos y comunitarios no monetarios, y en la base de todo la economía de la propia naturaleza, que son los pisos que sustentan todo lo de arriba. Pues aunque no se puedan o deban contar las relaciones los ecosistemas para ser intercambiados, son la base de los valores de la vida y de uso humano más imprescindibles. Profundizando en este tipo de esquemas, por ejemplo, lo que aportan la economía feminista (Carrasco, 2005) o desde la ecológica (Naredo, 2009) son sustanciales para entender lo que se propone a continuación.

El esquema que presento tanto se puede leer como izquierda-derecha o como arriba-abajo, o abajo-arriba ${ }^{3}$. La Financiarización Neo-liberal en este esquema ocupa el puesto de lo alto de la pirámide, pues la crisis actual la muestra como la verdadera convergencia de los intereses de la acumulación del capital con los poderes supra-estatales. En USA, en China o en la Unión Europea es difícil distinguir el papel estatal de las grandes transnacionales. Las luchas entre la llamada izquierda (neo-keynesiana) y la derecha (neo-liberal) son electorales, pero no de cambio de modelo en lo sustancial. Ambos bandos persiguen el crecimiento económico y el consumo. Los movimientos, sin embargo, protagonizan mucho más las luchas de los de abajo contra los de arriba. En el esquema se destacan las flechas que bajan con clientelismos y rivalidades, y las de las explotaciones y miedos. Se mantiene la Pirámide dominante (gracias a su izquierda con consumos públicos y su derecha con consumos privados), pero también se suman ahora los manglares rizomáticos emergentes (de los movimientos de abajo a arriba).

La metáfora de los manglares es porque tienen tierra abajo, con raíces con rizomas, la mar que oculta la mayor parte de los troncos, y una parte aérea que aflora. Lo que se ve es lo que aflora, pero lo importante es lo que no se ve, lo que sustenta. Las pirámides suelen ser sólidas y grandiosas, con piedras bien construidas, muchas de ellas son como monumentos funerarios al despilfarro de los poderes dominantes. El ojo de algún dios maneja las culturas patriarcales para presentarse como un Padre que pone orden en las rivalidades humanas, y maneja los fetichismos y los miedos para hacer trabajar a su servicio la explotación de la tierra y de los humanos. Pero hay una gran fuerza contrapuesta de abajo a arriba, con muchas líneas variables en emergencia, que van abriendo brechas entre las piedras, y que surge de las profundidades. Aparecen los Ecosistemas y Pro-comunes en las bases y fondos de la realidad invisibilizada, que tampoco son contemplados por la economía política dominante. Así los manglares emergentes pueden ser una metáfora útil para ilustrar lo que se quiere decir. Desde los fondos no monetarios e interacciones cotidianas y muy plurales, desde las ayudas mutuas y desde la creatividad social de los movimientos, hay una realidad que surge con buenas raíces.

${ }^{3}$ Los esquemas son solo una metáfora útil y están basados en las aportaciones de economistas como Karl Polanyi (2004) (sobre trabajos previos de K. Marx, M. Mauss, etc.), Elinor Ostrom (2011) sobre los bienes "pro-comunes", o José Manuel Naredo (1996, sobre economía ecológica y la actual "financiarización de la economía", y las otras crisis que se vienen encima). 
Cuadro 2: Pirámide dominante y movimientos emergentes

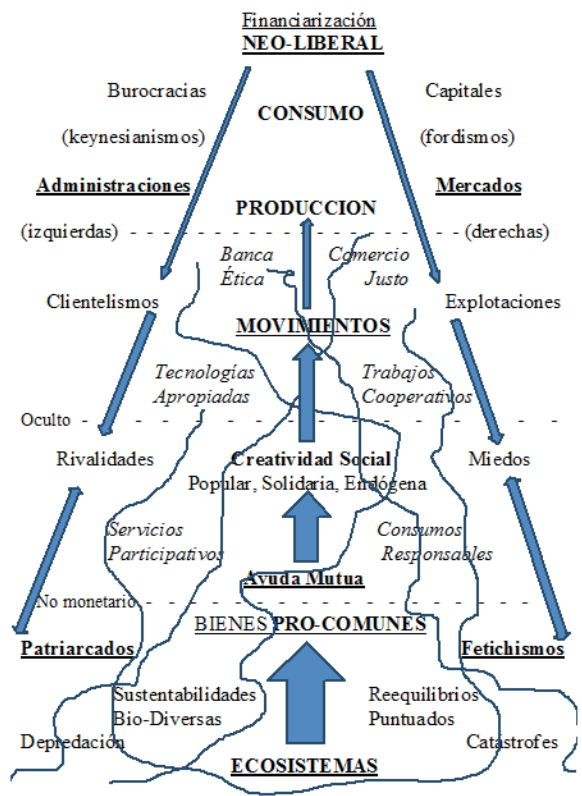

Fuente: Elaboración propia.

Los movimientos sociales son solo manifestaciones que se ven más o menos organizadas, pero entendemos por "conjuntos de acción" lo que son entramados sociales para acciones concretas, que articulan a varios actores de un mapeo o sociograma social, es decir actores no tan visibles, tanto de los poderes como de las bases potenciales, como de los propios grupos y movimientos. Pudimos aprender mucho de la naturaleza y de las relaciones de los ecosistemas, como el crecimiento de los manglares que es constante y basado en las raíces de forma rizomática (recordando la metáfora de Félix Guattari, 1990). También los "conjuntos de acción" entrecruzan actores que están invisibles para la dominación económica, hasta que emergen. Pero bajo el agua van creciendo como las economías informales, domésticas, populares, dentro de la Pirámide de la economía convencional. Suelen quedar ocultas las relaciones porque no se cuenta en monedas todo lo concerniente a la economía cotidiana no monetaria, y todos los aportes de la naturaleza. Es decir toda la "economía de cuidados y solidaridad familiar y comunitaria", y toda la "economía de recursos pro-comunes" como el agua, la tierra, etc. y la misma evolución de la naturaleza, la diversidad de los ecosistemas.

Lo más visible de la economía está en el triángulo superior entre las propuestas Neo-liberales dominantes (FMI, Agencias de calificación, etc.) en lo que se conoce 
como la financiarización de toda la economía. Lo que supone la máxima acumulación de capital, no a través de la producción misma, sino de los flujos especulativos de capitales y de las políticas burocráticas que apoyan esto desde las administraciones internacionales y regionales. A izquierda y derecha del triángulo superior, discuten tanto la propuesta "keynesiana" de relanzar el consumo público, o el "fordismo" de relanzar el consumo privado, pero en ambos casos es mejorar la economía mediante la ampliación del consumo. Se sigue debatiendo la rentabilidad solo en términos monetarios, donde la financiarización (y el consumo) bate a lo productivo. Fomentar una economía productiva puede ser más lento que el basarse en economías solo de consumo-finanzas, pero también parece más seguro a medio y largo plazo. A escala pequeña podemos ver el ejemplo de algunos sistemas cooperativos basados en redes de empresas de producción que incluso en el capitalismo (Schweickart, 1997) alcanzan la más alta tasa de productividad. A otra escala los países productores como China, van desplazando a los países consumidores, aunque estos aún tienen controlada la "financiarización" actual global.

Pero ni las economías financieras ni de consumo pueden subsistir sin las bases de la economía productiva. Al igual que la economía productiva no puede subsistir sin base en economías populares, en los pro-comunes (trabajo no pagado doméstico, colaboraciones de ayudas mutuas, etc.), ni en los ecosistemas (la tierra, el agua, la energía, etc.). Despilfarrar los ecosistemas es un suicidio a medio plazo para las comunidades. Pero las economías de producción están en crisis en muchos países por la mayor rentabilidad a corto plazo que puedan ofrecer las finanzas. Existen contradicciones dentro del propio sistema capitalista, pues es más lucrativo especular con dinero prestado que producir bienes y servicios. Unas economías no pueden vivir sin otras, pero las que dan más ventajas son las más improductivas y que sobre-explotan a la naturaleza, y por lo mismo las que más atraen las principales inversiones. La crisis que vivimos se basa precisamente en las expectativas generadas por los beneficios de la especulación, y el caso es que los remedios dominantes propuestos siguen jugando en el campo de las calificaciones de confianzas de la especulación financiera.

La economía de producción no deja de tener también sus problemas, en primer lugar en lo ambiental por sobre-explotación de los recursos finitos. Los combustibles fósiles se agotan y no se renuevan, los campos tienen sus ritmos de recuperación, etc. Pero además ya sabemos de la explotación de trabajadores en muy diversos tipos de empresas, y de las protestas de los movimientos obreros contra la condición del trabajo asalariado. A lo que hay que añadir políticas clientelares o corruptas con entidades del Estado, pues no se puede entender la economía sin la influencia administrativa de leyes y regulaciones. Todo ello hace un conjunto de "flechas" que bajan en el esquema desde el triángulo de arriba hasta las bases. ¿Por qué consiguen mantener esas dinámicas perversas? No se podrían mantener si en las bases no hubiese rivalidades y miedos sociales muy generalizados, aspectos de la cultura que son alimentados por la educación 
patriarcal-autoritaria y por los fetichismos en que vivimos. Aspectos que analizo en mayor profundidad en el libro Redes de vida desbordantes (2014).

De estas contradicciones de la producción económica y social surgen las llamadas Economías Populares y Endógenas. Para que la economía sea endógena debe basarse en los propios recursos locales y también centrarse en potenciar la localidad reinvirtiendo en la región propia. Pero tampoco podemos tomar toda la economía popular como endógena, ni solidaria. Por ejemplo, en Latinoamérica hay un amplio espectro de economía popular, del que es un magnífico ejemplo el Municipio de Villa El Salvador en Lima (Perú), desde cuando empezó esta experiencia en 1971. Pero en este país el debate es si la eficiencia de tales economías es para favorecer la economía local endógena o la particular de cada iniciativa. Puede haber economías exitosas, como en Villa El Salvador, o puede haber economías "productivas explotadoras y clientelares", desde "lo popular" como en muchos otros lugares. Desde los estudios de la "Terza Italia" hasta variados ejemplos en los países asiáticos y latinoamericanos, la economía endógena ha tenido éxito en muchas partes del mundo, y resiste mejor que otras las crisis que se han venido sucediendo.

Pero la "economía solidaria" es más que la endógena o la popular. Está dentro de estas, pero tiene una estrategia, consciente de los peligros en los que se mueve. No solo peligros de confrontar al sistema neo-liberal, sino también de cooptación por las economías de especulación o de consumo, y de peligros internos (competitividad, no profesionalidad, auto-explotación, etc.). La economía Solidaria se puede vincular con una economía endógena de producción para responder mejor ante las crisis. Y puede aprovechar las ventajas de los bienes pro-comunes. Los recursos de saberes y servicios de las comunidades son oportunidades diferenciales. Y la sustentabilidad de la naturaleza de los ecosistemas cercanos es la mejor base para no depender de mercados ajenos que no se controlan. De esta forma el recuperar y poder mantener, hacer emblema y poder distinguirse, a partir de los bienes pro-comunes (tradicionales o informáticos) de cada localidad y región, parece que es fundamental en las experiencias exitosas que se conocen en este campo. Los "certificados de calidad" populares o las "denominaciones de origen" oficiales, por ejemplo, dan testimonio de ello. Poner en valor (no solo de cambio, sino de uso) lo que está oculto a la economía convencional y aprovechar la fuerza de la ayuda mutua en muchas comunidades es lo que les ha permitido arrancar hacia una mejor calidad de vida.

Por ejemplo, en los Andes se intenta construir el Buen Vivir (Sumak Kawsay, Suma Qamaña), con el cooperativismo y la ayuda mutua, y se parte de una serie de elementos que funcionan en red entre ellos desde su propia cultura tradicional. Se interactúa con la economía internacional y la local, y toda estrategia está en función de lo que ocurre con las otras partes de lo cultural, social, la economía y la política, no solo los movimientos sociales (con la producción, migraciones, comercio, tecnologías, servicios, etc.) Cabe señalar la importancia de colaborar en los "conjuntos de acción" con entidades 
que defiendan el apoyo mutuo: 1.- Trabajos cooperativos, 2.- Consumos responsables, 3.- Servicios participativos, 4.- Tecnologías apropiadas, 5.- Mercados más justos, y 6.- Finanzas más éticas. Estas son algunas de las experiencias que hemos debatido en Latinoamérica para la economía de tipo solidario. De manera que los objetivos del Buen Vivir, o si se quiere de la Calidad de Vida, puedan aterrizar en propuestas concretas y viables. Pueden ser como las cadenas de valor o las redes endógenas, en donde cualquier elemento no puede actuar al margen de los otros seis elementos que se citan.

Se vienen otras crisis adicionales, desde el lado de los recursos en su cruce con las finanzas. El premio Nobel, J. E. Stiglitz (2010) comenta lo que se llama la "maldición de los recursos", pues por término medio, los países con grandes reservas de recursos naturales obtienen peores resultados que los menos ricos y los precios de los recursos naturales son efímeros. La actividad económica es incluso más volátil que los precios de las mercancías ya que, una afluencia de dinero hacia el petróleo provoca la apreciación de la moneda, la riqueza natural abundante crea países ricos con habitantes pobres. Si a esto le añadimos la "crisis alimentaria global" que se discute en todos los foros mundiales, y la reconversión de los espacios agrícolas a favor de los monopolios de este sector, el debate está en cómo prepararse para otras energías más renovables y recursos más controlables. La importancia del agua y la tierra, el viento y el sol, para la agro-ecología y las producciones locales pasa a ser vital. Y los ecosistemas sustentables con su capacidad endógena de resistir en estas nuevas condiciones a medio plazo.

Las crisis que se provocan con el manejo de la información también son contextos en los que cabe situarse. Por un lado, el no reconocimiento de los saberes y tecnologías tradicionales de las localidades es un desperdicio para las economías endógenas y solidarias. Además se van perdiendo las ayudas mutuas comunitarias, la información no se sabe tanto como contrastarla con amigos de confianza, y estamos más a merced de los grandes emporios de información. Emporios multimedia que se encuentran vinculados a intereses transnacionales hacen campañas en contra de las iniciativas económicas solidarias o los movimientos sociales que entienden que les pueden perjudicar. Se trata de una lucha prolongada entre la cúspide de la pirámide con grandes medios y muy concentrados, frente a unas iniciativas dispersas, que se mueven más con la comunicación cara a cara (o a través de internet) y que semejan más una maraña de troncos retorcidos que una plantación bien ordenada.

Cada movimiento, en las cadenas de valor de uso a medio plazo, ha de saber moverse en alianzas estratégicas para que sus recursos estén en un buen contexto sustentable. Pues solo desde una base económica eficiente se pueden conseguir buenos resultados también para el Buen Vivir, y para la Calidad de Vida. No hay porqué obsesionarse con el "nivel de vida" (más consumo de lo que sea), sino tratar de vivir mejor con lo que se necesita socialmente. Preferimos razonar no solo desde los movimientos de protesta, sino desde las propuestas. La transición y la transformación puede ser hacia un mejor convivir, construido colectivamente, y desde una viabilidad económica para alcanzar 
lo que pueda llegar a ser una mejor calidad de vida para la mayoría. Y en los términos que decida la gente que pueda ser el construir, por ejemplo, "las cuatro redes para mejor-vivir" (Villasante, 1998), o ese Buen Vivir responsable que ahora ya está hasta en algunas Constituciones de países latinos.

\section{Conjuntos de acción emergentes desde los fondos eco-sociales}

Estos debates no se plantean solo desde los condicionantes externos tal como se suele hacer en ciencias sociales sobre los movimientos sociales y sus características clasificatorias. En algunas textos de los 70-80 y hasta los 90 incluso, debatimos en esos términos sobre los movimientos sociales, pero nunca les interesó mucho a los propios militantes. Y además nunca se pudo ver que sirvieran tales análisis académicos para mejorar la eficiencia de sus esfuerzos. A los movimientos, en sus asambleas iles interesan estos debates? ¿A un movimiento le interesa saber que es un movimiento de tal tipo, o más bien cuando se dan estos debates desde la militancia tratan de desmarcarse de tales planteamientos? ¿O son otras las preguntas que se hacen los grupos activos y motores de los movimientos? Por eso interesan más las relaciones y estrategias de los "conjuntos de acción".

Pero también hay que reconocer que los movimientos no suelen saber mucho de sí mismos, aprenden poco de sus propias experiencias, y parece que están naciendo de nuevo cada vez. Incluso los más históricos, como el feminismo, los sindicales, el cooperativismo, etc. construyen historias y debates sobre sus conquistas, pero mucho menos sobre sus defectos y los errores por los que se pierden muchas conquistas sociales. Por eso parece más sensato pasar a otras preguntas básicas, que surjan desde la propia gente que está en los movimientos. Esto ha sido un punto de arranque para la "investigación-acción-participativa" (Fals y Rodríguez, 1986), para el "socio-análisis" (Lourau, 1975; Lapassade, 1980) y para muchos otros (Freire, 1970; Guattari, 1976). No hemos querido quedarnos encerrados en los esquemas y conceptos externos y desde arriba que observan a los movimientos y a la sociedad a vuelo de pájaro. ¿Preguntas y distinciones para clasificar, o para dinamizar y transformar, con estrategias concretas y auto-construidas, desde dentro y desde abajo? Estas segundas preguntas son nuestros objetivos y nuestras metodologías participativas, para lo que nos sirven estos enfoques.

Se han hecho muchos análisis de los "movimientos sociales" como tales (Touraine 1996), (Castells 1998), (Melucci, 1994), o sobre la "estructura de oportunidad política" (Tilly, 2010), (Tarrow, 2004). También está el debate sobre las clases sociales (Bensaid, 2004), el concepto de "pueblo" (Laclau, 2005); sobre "multitud" (Negri, 2005; Virno, 2003), la ciudadanía, o "cualquiera" (Rancière, 2006), y más recientemente ha hecho fortuna "somos el 99\%" Ocupy Wall Streat (OWS). Pero todos son más bien debates teórico-abstractos o consignas ¿Para qué sirven todos estos conceptos? ¿A quién le 
son útiles, para qué pueden valer conceptos "atrapa-lo-todo"?. Pueden servir en algunos ambientes y grupos de "enterados" que discutan sobre el "sujeto histórico" de la revolución. Lo que ya presupone que hay una "historia con sujetos" y que algunos teóricos saben o discuten cuáles son o pueden ser. Tratamos de preguntarnos más por "las historias" como multi-causalidad (que por "La Historia"). Y acerca de los "sujetos" en debate vamos a argumentar que nos parecen más transformadores sus vínculos y relaciones que ellos mismos. Los "conjuntos de acción" se basan en los mapeos de relaciones sociales en cada coyuntura concreta.

Lo que mueve, de forma más inmediata, a los movimientos sociales es su capacidad de crear vínculos tanto con su entorno cotidiano como en su interior auto-organizativo. Es decir, sin despreciar otros componentes de los sujetos (fracciones de clases sociales, programas o identidades) las formas de vincularse en cada vida cotidiana es la clave de éxito o fracaso de forma más inmediata. Esto lo hemos podido comprobar en los estudios de los años 80 y 90, en más de 20 casos en Madrid (Villasante et al., 1989), y en Latinoamérica también en más de 20 casos (Villasante et al., 1994), pues aún con condiciones de clase similares y con unas identidades y programas semejantes, los resultados eran muy dispares. Y de forma muy notable la capacidad de organización y relaciones internas y externas era el factor clave para explicar el proceso de los movimientos sociales.

Lo que podemos llamar "conjuntos de acción" (que nos dan los análisis de redes del tejido social circundante), y la auto-organización interna son los aceleradores o los bloqueadores principales para que los movimientos puedan tomar unas u otras decisiones. Así como con los factores externos es difícil cambiar sus condicionantes en un conflicto, sí es posible cambiar el tipo de relaciones internas y con las comunidades cercanas. No van a cambiar los sujetos, porque están condicionados por sus características estructurales, y por sus identidades adquiridas, pero los sujetos sí pueden elegir cómo auto-organizarse y relacionarse con alianzas y con sus bases de apoyo potenciales. Aunque tampoco esto es sencillo, pero siempre es más fácil cambiar de estrategias relacionales que de identidades. O sea, para los movimientos se trata de cambiar de relaciones más que de los principios que informan a los sujetos, cambiar más los vínculos que los sujetos.

Al cambiar las estrategias de los vínculos con los sectores de base o con otros "conjuntos de acción" se practican otras formas de movilización y resultados. Que a su vez son los que pueden hacer cambiar las identidades. Pues en el fondo, las identidades son más bien "identificaciones" que han sido construidas. Al practicar el movimiento unas relaciones diferentes con sus bases, o cambios en su auto-organización, o alianzas de otro tipo, las identidades se abren a identificaciones que van surgiendo por sí mismas. Y son los propios movimientos quienes pueden decidir estas estrategias si se construyen con ellos "mapeos" de sectores de base, de otras organizaciones y de los poderes que influyen en el conflicto. Estas variables son útiles a los movimientos si las utilizan, porque contribuyen a establecer en cada caso cómo pueden actuar mejor. No 
solo es la clasificación de características externas e internas, sino herramientas para la actuación inmediata.

Se acerca a los "conjuntos de acción" los "repertorios de movilización" si recogen "hábitos cotidianos y organización interna"... "tradiciones"... "experiencias de acción colectiva"... "represión...de cada Estado". Aunque los análisis de (Tilly, 2010) se centran más en la historia, y es el historiador quien los determina, al menos analiza las conexiones entre actores y mecanismos internos como comenta (Tarrow, 2004). Lo interesante de estos enfoques de un "constructivismo relacional-realista" (Máiz, 2007) es que llegan a pensar un repertorio de acción como si fuera una entidad ontológicamente reales, y no como un concepto teórico. Consideramos de especial interés el nuevo concepto de redes de confianza (trust networks) fundadas en relaciones y no meras disposiciones. Aunque no parece que sean tan innovadoras estas redes de confianza, cuando (Elias, 1982:97) ya venía trabajando con "entramados"; o desde la Escuela de Manchester de antropología con "análisis de redes", "cuasi-grupos", "conjuntos de acción", etc.; o nosotros aplicábamos los "conjuntos de acción" construidos por los propios movimientos sociales a través de los mapeos y sociogramas.

Pero en cualquier caso es más interesante y más concreto y operativo, que retomar los debates sobre el "sujeto histórico", si es la clase, el pueblo o la multitud, por ejemplo. Salvo para descartar que no es un determinismo de clase lo que nos mueve, y que hay otros factores a tener en cuenta, estos debates teórico-ideológicos la mayor parte de las veces solo sirven para justificar sectarismos de unos grupos con otros. En la medida en que estos conceptos se usan genéricamente no sirven, pues no se concretan como en Engels en la "condición de la clase obrera en Inglaterra" o como en las "contradicciones en el seno del pueblo" de Mao Tse-tung, o en los "mapeos de las "mareas indignadas" de esta última crisis. Podemos discutir mucho sobre ciudadanía, multitud, pueblo, clase social, pero aún se sigue lejos de cualquier "análisis concreto de la situación concreta", que siempre incluye muchos condicionantes, muchas contradicciones. Son conceptos que se usan más para bloquear acuerdos que para hacer estrategias conjuntas y transformadoras.

Es un enfoque teórico-metodológico lo que se está proponiendo. Con estas reflexiones queremos volver a conceptos básicos de las inter-acciones de la vida cotidiana, desde la propia gente que es potencial de cualquier movilización significativa. Sin negar las características de clase y las identificaciones de cada movimiento, nos podemos centrar en aspectos relacionales internos y externos, considerando otras variables como "los entramados", "los repertorios de interacción", o "los conjuntos de acción". Lo más novedoso que aportamos a un debate es la posibilidad de hacer con los propios colectivos o movimientos los auto-diagnósticos integrales, con todas sus variables articuladas, para sus propios fines.

Para entender bien estas lógicas de lo relacional vale la pena hacer un recorrido por los fundamentos de la vida, por lo que se suele conocer como "sistemas emergentes". 
Es desde los "fondos eco-sociales" desde donde mejor podemos retomar en profundidad los "juegos" y "entramados" de (Elías, 1994), el análisis de redes de la "Escuela de Manchester" (Wolf et al., 1980), o los "repertorios de interacción" (Tilly, 2007) para elegir espacios y relaciones. Los "fondos de empatía" de (Varela, 1998), conectan con la "evolución del talento" (Bermúdez, 2010) y las "redes exo-cerebrales" (Bartra, 2006). Todos estos enfoques, desde muy variadas disciplinas y autores, vienen a coincidir en la capacidad relacional de los humanos que fundamentan nuestras formas de hacer, aún de manera preconsciente. En la "Sociología Fundamental" (Elias, 1982: 97) afirma, a cerca de los juegos de poder, que "El poder no es un amuleto que uno posea y otro no; es una peculiaridad estructural de las relaciones humanas -de todas las relaciones humanas." Y a continuación entra en el fondo social, o sea un "Pre-juego: un modelo de entramado no normado... modelo de relación no regulada, recuerda que toda relación entre personas es un proceso... Solo es posible entender y explicar la sucesión de actos de ambas partes en su mutua interdependencia." Y de esta manera "Este modelo deja espacio para diversas constelaciones de equilibrio de poder."

En los "conjuntos de acción" también comprobamos que cada proceso, como en Elias, "efectúa sus jugadas simultáneamente dentro y fuera de una red de jugadores interdependientes en la que hay alianzas y enemistades, cooperación y rivalidad en diversos planos. En un juego de dos pisos cabe imaginar como mínimo tres, tal vez cuatro, equilibrios de poder diferentes que encajan como las ruedas dentadas de un mecanismo..." Es útil para los movimientos saber dónde puede estar su fuerza y las de sus grupos, afines, diferentes, ajenos o contrarios, que es lo que trabajamos con los "conjuntos de acción", pues no se trata tanto de saber de una identidad como de una constelación de identidades. Siguiendo a (Elías, 1982: 103): "Su fuerza de juego descansa en este caso en la comprensión y habilidad con que sea capaz de aprovechar las oportunidades ofrecidas por la constelación de equilibrios de poder haciendo de ellas la base de su estrategia".

En un trabajo de Granovetter (2000) sobre análisis de redes, "la fuerza de las relaciones débiles", apunta también en este sentido. Y de nuevo en (Elias, 1982: 112) se profundiza: “... más allá del horizonte de las llamadas teorías de la acción. Registran, de todos modos, que interacciones intencionales tienen consecuencias no intencionadas. Pero ocultan el hecho central para la teoría de la praxis de la sociología de que en la base de toda interacción intencionada hay interdependencias humanas no intencionales. Tal vez sea el modelo del pre-juego el que más directamente ponga esto de manifiesto... del entramado de las acciones de muchas personas pueden derivarse desarrollos no planeados por ninguna de ellas." Los sujetos han de estar conscientes de esas figuraciones de entramados ya que "Entre las condiciones de esta figuración se hace especialmente patente el carácter auto-regulado, la autonomía relativa de los procesos de entramado frente a los sujetos que se interrelacionan." 
Para manejar estas relaciones usa la herramienta gráfica de "figuración" (como nosotros hemos tomado del análisis de redes el concepto de los "conjuntos de acción"), "sencillo instrumento conceptual con ayuda del cual flexibilizar la presión social que induce a hablar y pensar como si "individuo" y "sociedad" fuesen dos figuras no solo distintas sino, además, antagónicas." Basándose en los "entramados"... "la figuración que constituyen los jugadores es tan concreta como ellos mismos... Como se ve, esta configuración constituye un tejido de tensiones."... Así "su referente no son ya solo personas, sino también, cada vez más, símbolos de las unidades más grandes, escudos, banderas o conceptos llenos de carga emotiva. Estas vinculaciones emocionales de los hombres entre sí a través de fórmulas simbólicas no tienen una importancia menor para interdependencia que las vinculaciones antes mencionadas debidas a la creciente especialización. De hecho, los distintos tipos de vinculaciones afectivas son inseparables." Desde estos fondos emocionales el juego de poder es complejo. En el entramado de jugadas de muchos jugadores interdependientes no hay jugador individual por muy poderosos que puedan ser:

Los desarrollos sociales, vistos a largo plazo, se mueven ciegamente, sin dirección alguna - tan ciegamente - y faltos de dirección como un juego. La tarea de investigación sociológica consiste en aplicar el entendimiento humano a estos procesos ciegos y carentes de dirección; la tarea consiste en explicarlos y a través de ello, posibilitar a los hombres la orientación en los entramados producidos por sus propias acciones y necesidades"... Nosotros preferimos que sean los movimientos los que hagan esa tarea, aunque sea con la ayuda-distanciamiento de profesionales comprometidos. Por ejemplo saltar a un nuevo paradigma como se saltó de una constelación geocéntrica a una heliocéntrica necesitó de un acto específico de distanciamiento, también el paso de una visión de la sociedad centrada en torno a la propia persona o al grupo con el que no se identifica a otra en la que uno mismo o su grupo ya no constituyen el centro, requiere un acto específico de distanciarse. Al igual que en (Elias, 1982), estos distanciamientos de conceptos los vemos en otros autores más actuales, pero casi todos apuntan a aprender de la vida y de sus sistemas emergentes.

Los movimientos de descolonización consiguieron las independencias políticas de las metrópolis, pero no consiguieron descolonizar la cultura dominante, y menos las dependencias económicas que aún perduran. La defensa de sus países frente a un enemigo común, con sus frentes unitarios, y con formas inclusivas, son una buena base que se mantiene en los más nuevos movimientos. Los movimientos indígenas y campesinos del sur del planeta en las últimas décadas han sido protagonistas de las luchas más sonadas y la recuperación de sus sabidurías, su ecología y seguridad por la soberanía alimentaria. Y sin duda los movimientos feministas y de mujeres en general también han contribuido a nuevos valores que van construyendo los movimientos de este siglo. El cuidado cotidiano de la vida, las críticas a los elitismos patriarcales y autoritarios, etc. se ven en los movimientos de este siglo, pero ya generalizados. 
Tabla 1: “Conjuntos de Acción” Respondiendo a “preguntas emergentes"

\begin{tabular}{|c|c|c|c|c|}
\hline $\begin{array}{l}\text { Preguntas emergentes } \\
\text { Conjuntos de Acción }\end{array}$ & $\begin{array}{l}\text { ¿Reversivos } \\
\text { anónimos? } \\
\text { ¿Sin siglas? }\end{array}$ & $\begin{array}{l}\text { ¿Democracias } \\
\text { desde abajo? } \\
\text { ¿Sin jefes? }\end{array}$ & $\begin{array}{l}\text { ¿Idea-fuerza } \\
\text { inclusividad? } \\
\text { ¿Sin miedo? }\end{array}$ & $\begin{array}{l}\text { ¿Inteligencia } \\
\text { colectiva? } \\
\text { ¿Sin dogmas? }\end{array}$ \\
\hline $\begin{array}{l}\text { Descolonización } \\
\text { y anti-autoritarios } \\
\text { (Frentes populares, } \\
\text { Kerala, ...) }\end{array}$ & $\begin{array}{l}\text { Defensa de los } \\
\text { valores locales, } \\
\text { ecología y cultura } \\
\text { de lo común. }\end{array}$ & $\begin{array}{l}\text { Frentes } \\
\text { populares } \\
\text { con un líder } \\
\text { histórico. }\end{array}$ & $\begin{array}{l}\text { Suma de clases } \\
\text { sociales contra } \\
\text { un explotador } \\
\text { común. }\end{array}$ & $\begin{array}{l}\text { Unidad } \\
\text { programática } \\
\text { de mínimos } \\
\text { contra el } \\
\text { enemigo } \\
\text { común. }\end{array}$ \\
\hline $\begin{array}{l}\text { Indígenas y } \\
\text { campesinos } \\
\text { (Ecuador, Bolivia, } \\
\text { Chiapas y MST) }\end{array}$ & $\begin{array}{l}\text { La madre tierra y } \\
\text { los tiempos largos } \\
\text { de cada cultura. }\end{array}$ & $\begin{array}{l}\text { Asambleas con } \\
\text { costumbres } \\
\text { y ritos } \\
\text { tradicionales. }\end{array}$ & $\begin{array}{l}\text { Seguridad } \\
\text { y soberanía } \\
\text { alimentaria. }\end{array}$ & $\begin{array}{l}\text { Sabiduría } \\
\text { ancestral de } \\
\text { escuchar las } \\
\text { diferencias. }\end{array}$ \\
\hline $\begin{array}{l}\text { Mujeres y eco- } \\
\text { feminismo } \\
\text { (vida cotidiana, } \\
\text { cuidados y vida } \\
\text { reproductiva) }\end{array}$ & $\begin{array}{l}\text { Ser la mitad del } \\
\text { mundo en la } \\
\text { población y dar la } \\
\text { vida. }\end{array}$ & $\begin{array}{l}\text { Valorar los } \\
\text { cuidados y el } \\
\text { servicio de lo } \\
\text { cotidiano. }\end{array}$ & $\begin{array}{l}\text { Valorar la } \\
\text { reproducción } \\
\text { y el hacer no } \\
\text { asalariado. }\end{array}$ & $\begin{array}{l}\text { Critica del } \\
\text { patriarcado } \\
\text { y del } \\
\text { productivismo }\end{array}$ \\
\hline $\begin{array}{l}\text { Metodologías } \\
\text { participativas } \\
\text { (educación popular, } \\
\text { presupuestos } \\
\text { participativos, ) }\end{array}$ & $\begin{array}{l}\text { Descentralización, } \\
\text { resiliencias y } \\
\text { reversiones. }\end{array}$ & $\begin{array}{l}\text { Cartografías de } \\
\text { escucha y redes } \\
\text { desde abajo. } \\
\text { Asambleas con } \\
\text { grupos. }\end{array}$ & $\begin{array}{l}\text { Planes } \\
\text { participativos, } \\
\text { y viabilidad } \\
\text { de economías } \\
\text { solidarias. }\end{array}$ & $\begin{array}{l}\text { Talleres de } \\
\text { creatividad } \\
\text { social y } \\
\text { desbordes } \\
\text { transductivos. }\end{array}$ \\
\hline $\begin{array}{l}\text { Tecnologías libres y } \\
\text { anónimas } \\
\text { (hackers, anonimus,) }\end{array}$ & $\begin{array}{l}\text { Deslocalización y } \\
\text { espacios virtuales, } \\
\text { con rapidez casi } \\
\text { instantánea. }\end{array}$ & $\begin{array}{l}\text { Hackers } \\
\text { anónimos } \\
\text { y ciber- } \\
\text { democracias. }\end{array}$ & $\begin{array}{l}\text { Velocidad y } \\
\text { multiplicación } \\
\text { de las } \\
\text { interacciones. }\end{array}$ & $\begin{array}{l}\text { Comunicación } \\
\text { viral e } \\
\text { incontrolada. }\end{array}$ \\
\hline $\begin{array}{l}\text { Contra-cumbres y } \\
\text { tomar plazas } \\
\text { (0'7\%, FSM, } 15 \mathrm{M} \text {, } \\
\text { OWS, etc.) }\end{array}$ & $\begin{array}{l}\text { Contra el cambio } \\
\text { climático, y a favor } \\
\text { de los pro-comunes }\end{array}$ & $\begin{array}{l}\text { Portavoces } \\
\text { rotativos, } \\
\text { asambleas, } \\
\text { fiestas, etc. }\end{array}$ & $\begin{array}{l}\text { Contra la } \\
\text { especulación } \\
\text { financiera, } \\
\text { democracia } \\
\text { real, del 99\% }\end{array}$ & $\begin{array}{l}\text { Ecología } \\
\text { de saberes, } \\
\text { creatividad } \\
\text { colectiva. }\end{array}$ \\
\hline
\end{tabular}

Fuente: Elaboración propia.

Estamos ante un cambio generacional y cultural que trae otras formas de organizarse que supone que las democracias más participativas y radicales sean posibles. Y esto empieza a ser un gran avance en la construcción de poderes paralelos a las democracias representativas. En las experiencias de los Presupuestos Participativos muchos políticos preguntan: “¿y ahora qué vamos a hacer nosotros, si es la gente quien decide?” Pues aún les queda ejecutar lo que quiere la gente, que no es poco si lo hacen bien. Pero ellos ya están 
notando que está naciendo otro poder en paralelo (y por eso no lo suelen ver con buenos ojos), que es posible tomar las decisiones de abajo a arriba, y con más legitimidad directa desde las necesidades de la gente. Son unas nuevas metodologías participativas.

Algo está pasando a escala mundial, como ocurrió en el final de los años 60 (California, Alemania, México, Paris, Praga, Italia, etc.), y que hoy podemos ver en los movimientos surgidos en el norte de África, el sur de Europa, Chile, Brasil, México, China etc. donde se van retomando formas de hacer unas políticas más democráticoparticipativas. Un nuevo ciclo de movilizaciones en el mundo está abriendo unas nuevas transiciones para la construcción desde debajo de unas nuevas democracias reales (económicas y sociales). Las nuevas democracias de base, que se van construyendo por todo el mundo en diversas modalidades, tienen mucho que enseñar a las democracias electorales hasta ahora conocidas. Además también ponen retos al uso democrático de las nuevas tecnologías y redes sociales, y aún deben aprender ellas mismas unas de otras. No estamos más que en el principio de una nueva era de democracias más reales, no tan formalistas y/o elitistas como las representativas actuales. Y esto es solo el comienzo.

No es la crisis, es el sistema lo que está en juego. Esta idea-fuerza está calando en muchos movimientos sociales y en esta toma de conciencia se ven avances reales de un continente a otro. Por eso no hay razón para mirar con recelo lo que experimentan las generaciones más jóvenes, sino tener más bien la ilusión de que nos puedan enseñar en la construcción colectiva que se está iniciando. En cualquier caso estamos en un cambio de época, en donde los tres poderes tradicionales de la economía y la política (EEUU, Europa, Japón) se ven amenazados y desplazados por las nuevas potencias emergentes (China, India, Brasil, Rusia, etc.). Los cambios en las materias primas energéticas y en lo alimentario, en lo financiero, parece que nos coloca en nuevos retos tanto para las clases medias como para los sectores más populares. Hay una generación o dos en las que se van a jugar grandes bazas para el futuro de la humanidad. Los 2.000 millones de habitantes, que aún se esperan, van a llegar al mundo inmediato y vienen a aumentar los problemas de los sures desheredados. Y las clases medias, profesionales cada vez más formadas, se están indignando ante las incongruencias y escándalos del actual sistema financiero y especulativo, los problemas climáticos y alimentarios, etc. Es en esta situación en la que cabe una articulación de intereses sociales muy amplia para luchar por propuestas de vida sustentables.

\section{Grupos Motores hacen emerger procesos de creatividad social}

Se trata de unos grupos heterogéneos en su composición, que ven clara una actividad o acción común, y habitualmente bastante concreta. Ejemplos pueden ser los grupos que dinamizan voluntariamente un Plan Comunitario o unos Presupuestos Participativos, un movimiento o "marea" en un colegio o un hospital, una cooperativa que se está creando, 
etc. Con sus primeros pasos puede ser un grupo promotor de algo concreto que se está creando y que luego se institucionaliza o no, según cómo vaya el proceso. Se pueden distinguir los grupos motores como algo diferente de las Comisiones de Seguimiento, de las Plataformas Unitarias, de las uniones y alianzas locales o sectoriales, donde representantes de varios grupos se ponen de acuerdo para acciones concretas o para tareas unitarias desde su diversidad. En los grupos motores no hay representantes, sino sobre todo las personas que (a titulo singular) quieren comprometerse por un tiempo a una tarea que le parece interesante. Son grupos relativamente pequeños que se proponen promover, desde un acuerdo concreto "para esto" y por un tiempo limitado, alguna actividad conjunta.

Los "grupos motores", tal como los hemos experimentado, tienen varias características que los hacen un tanto diferentes de los grupos de vanguardia o pedagógicos habituales. No son grupos de una determinada ideología o programa, pero tampoco son plataformas de representantes de sectores que se coordinan circunstancialmente. Hay personas de diversas ideologías y puede haber líderes de algunos sectores, pero no es lo fundamental. Es mucho más significativo que haya una pluralidad y diferencias que permitan una cierta creatividad social, es decir, que se cree un buen ambiente donde las diferencias (de género, de edad, entre voluntarios y profesionales, de ideologías, o incluso de etnias) se vuelvan en factor enriquecedor para todas las partes. Son grupos de iniciativas en los que se aprecia que las cosas funcionan y además la gente aprende y se lo pasa bien. No quiere esto decir que no haya discusiones, y que no haya esfuerzos y trabajos voluntarios. Pero todos los esfuerzos se ven recompensados porque las tareas pueden ir resultando sin un peso excesivo para unas pocas personas. La diferencia en estos grupos hace la creatividad, este es su principio de referencia. En este sentido podemos decir que son "grupos inteligentes". Las diferencias hacen que fluya la creatividad social tanto para situarse los grupos motores como tales, como para crear situaciones hacia los tejidos sociales cercanos.

Vemos que en los "grupos motores", por un lado, se mezclan distintos sectores profesionales o voluntarios, con unas ideologías u otras, pero con algún objetivo concreto común y con metodologías participativas claras y acordadas por todo el grupo. Son instituyentes tal como lo que Guattari llamaba "grupos-sujeto". Por ejemplo los grupos "ad hoc" en algunos procesos comunitarios, los presupuestos participativos, la autogestión de centros sociales, campañas populares, etc. Estas tareas se colocan por encima de las ideologías o motivaciones particulares de cada persona. O sea, que cada cual se guarda su posición concienciadora "en el bolsillo". Se centran en la escucha, en la autoformación, en la creatividad colectiva, mostrando en la práctica operativa del proceso, en cada tarea concreta, cómo sirven mejor la construcción de la acción y el conocimiento colectivo, y no tanto partiendo de debates de principios teóricos. Aparte de estos grupos, sin duda puede haber unos espacios de Foros o Jornadas para todo tipo de debates ideológicos, o puede también haber unas Plataformas y Comisiones Unitarias para que los representantes de la comunidad sigan el proceso. Pero los "grupos motores" no son 
eso, sino más bien unos grupos de una tarea conjunta que preparan, sirven y dinamizan al proceso más allá de sus diferencias.

Estos dispositivos de inteligencia colectiva, para fomentar la creatividad social, los veníamos usando a pequeña escala en procesos más o menos de tipo profesional o implicativo. Pero los movimientos de los "indignados" lo han llevado a una escala sin precedentes, si bien es cierto que a su manera y sin llamarlos así, sin ser del todo conscientes de toda la potencialidad que abren. La misma forma de auto-organizar procesos de tomar las plazas y preparar las asambleas les ha llevado a reunirse en comisiones y grupos de trabajo diferenciados. Se comprueba que las formas de auto-organización no son tan espontáneas y sin grupos, no niegan los grupos de iniciativas, lo que llamamos "grupos motores", sino que los refuerzan. Son la continuidad por internet y por asambleas de las nuevas formas de construcción colectiva de la inteligencia creadora. Hay muchos grupos de iniciativas desde abajo. Son grupos que no pretenden ser las vanguardias o los representantes de los movimientos sociales, aunque sí pretenden lanzar algunas iniciativas sin afán de protagonismo. Los grupos motores adoptan diversas formas; de amistad, de experiencias comunes, de temas que les motivan, etc.

Lo más interesante y novedoso es que se buscan formas y se intenta que no aparezcan personalismos ni siglas que puedan perturbar el debate de ideas o propuestas por sí mismas. Sin duda hay ideologías, hay siglas y hay personalismos, pero se trata de que interfieran lo menos posible como elementos de distorsión, pues por las experiencias se sabe que han dividido más que agregado en los movimientos sociales. Una de las diferencias de los "grupos motores" con los "partidos políticos" es que estos han tratado de capitalizar y dirigir a los movimientos desde alguna posición ideológica más o menos cerrada o dogmática. En cambio en los "grupos motores" hay más una posición de servicio y estilo participativo, pues las ideologías de cada cual se guardan, mientras que las propuestas de acción concreta son las que prevalecen más. Ganar una buena diversidad es signo de creatividad y de enriquecimiento colectivo, y por eso les parece positivo no partir de una unidad a la que se deben sumar otros, sino de hacer un camino desde la diversidad para ir construyendo de manera colectiva.

Estos grupos no tienen por qué ser familiares o de tipo ideológico, sino que pueden surgir en el trabajo o en alguna tarea, en el vecindario, en los estudios o entre amigos simplemente. Pero son "puentes" muy útiles en los circuitos de comunicación cara a cara, son la base de la generalización de acciones y de los conocimientos, porque se mueven entre las redes del tejido social en la vida cotidiana, y hablan en los mismos lenguajes que la gente de su entorno y ambiente. Precisamente, si no se les supone un interés familiar, económico o ideológico, estos grupos son más creíbles para la población y de ahí su eficacia y su buen ambiente. Esto no quiere decir que no puedan tener posiciones radicales, socio-políticas o transformadoras, pues en los movimientos las están teniendo, por ejemplo. Pero no se les identifica con un partido en concreto o con una iglesia en particular, que pretenden meter sus teorías por principio. 
Son grupos más metodológicos (más o menos informales) y no tanto ideológicos. Conforman guías para la acción, pero con unos contenidos "cuidadosos", una profunda crítica a las estructuras patriarcales. No es tanto tratar a todos por el mismo rasero, sino cuidar de cada uno "según sus necesidades", para potenciar a cada cual "según sus capacidades". No avanzan sin que la gente se meta en papeles protagonistas. Pero un protagonismo no para el grupo en sí, sino para repartirlo entre los sectores implicados. Para que se pueda consolidar, tal vez avanzando más despacio, pero desde la auto-formación práctica de los sectores de base, experimentando por sí mismos. No se potencia la creatividad de algunos líderes, sino la creatividad social en sus ambientes cotidianos, con los "conjuntos de acción". Fomentando los cuidados, sobre todo en los "grupos motores", estos hacen de puentes entre "conjuntos de acción". Es decir, construyen estrategias de acción y conocimientos en "común", llevan los debates a las tareas prácticas, para servirse de las teorías aplicándolas en los procesos concretos. Aprovechan las diferencias de orígenes de quienes participan para construir creatividades sociales muy aplicables a la mayoría de la gente.

Los "grupos motores" pueden ser unos buenos centros de elaboración de las estrategias para construir "otros poderes-para", que desborden a los actuales de tipo patriarcal y elitistas. Abrirse a escuchar a la variedad de sectores populares es algo que nos llevará a precisar qué "conjuntos de acción" tienen potencialidades para la transformación social en cada caso. Y desde ahí establecer talleres, reuniones, y otras formas de colaboración para dinamizar o "transducir". Por ejemplo lo que llamamos "talleres de creatividad social", o sesiones para construir auto-diagnósticos desde los sectores implicados, confianzas en que podemos trazar líneas de actuación comunes, al menos para algunos objetivos muy concretos. Estos "grupos motores" no tienen soluciones, pero sí pueden activarlas escuchando y haciendo puentes, provocando saltos con las construcciones colectivas y creativas, en donde los participantes se sienten protagonistas y no unas meras correas de transmisión. Estos grupos pueden apostar por dar el mayor protagonismo a las redes auto-reguladas, con talleres, grupos de trabajo, asambleas, plenarios, etc. de forma que se tiendan a eliminar los patriarcalismos en que hemos sido educados. "De cada cual según su capacidad, a cada cual según sus necesidades" que es una buena pauta, seguramente compleja, pero muy acertada, para poder ser creativos y a la vez transformadores.

\section{Resumiendo la estrategia implicativa ambiental}

El objetivo de este artículo ha sido presentar un enfoque participativo que sirva a los "grupos motores" de procesos socio-ambientales para enfocar sus estrategias, basándose en las relaciones que puedan descubrir en los "conjuntos de acción" tal como los puedan analizar. Para ello planteamos una posición diferenciada de los "grupos motores" de otros grupos ideológicos o de coordinaciones de los movimientos habituales. O sea no 
hay que centrarse tanto en identificar y calificar a los movimientos por sus programas, desde juicios de principios absolutos, sino en que cada grupo pueda llegar a analizar por sí mismo sus "conjuntos de acción” en cada situación concreta, y desde ahí poder construir sus estrategias de alianzas.

Los "conjuntos de acción" son enfoques basados en mapeos de actores, en la complejidad de las variables básicas de cada situación concreta (clase social, identidad ambiental, organización simbólica, relaciones cotidianas), que van más allá de identificar a un movimiento al margen de su entorno de relaciones. Las relaciones de vida cotidiana son tan importantes como las otras variables, y condicionan las estrategias de manera muy importante. Se basan no solo en lo visible de los grupos o movimientos, sino en los fondos eco-sociales que no se suelen percibir en una primera reflexión. Por eso es conveniente hacer la auto-reflexión escuchando las sintonías de fondo del mar y no solo las apariencias superficiales.

Estos "conjuntos de acción" no se asemejan a un movimiento social o un ejército bien ordenado. Se asemejan más a los "manglares", tanto a la hora de construirse de abajo hacia arriba, desde los fondos ocultos de la tierra y los mares, como en la forma de enfrentar las luchas frente a las pirámides del poder constituido. Tienen en cuenta las economías dominantes, y sus contradicciones, en la medida en que se nos muestran bastante descaradas desde la "financiarizacion", pero apuntan a tener bien plantadas su raíces en las ayudas mutuas, economías solidarias, en los bienes pro-comunes, en las características de los ecosistemas locales. Se trata de aprender en las ciencias sociales y en los movimientos ambientales de los "manglares" y su construcción desde abajo, desde lo que se teje en la vida cotidiana.

\section{Bibliografía}

Agamben G., A. Badiou, D. Bensäid, W. Brown, J-L. Nancy, J. Rancière, K. Ross y S. ZizeK (2010): Democracia en suspenso, Madrid, Casus-Belli.

Antunes C. et al., (1994): Manifiesto Eco-socialista, Madrid, Libros de la Catarata.

BraidotTi, R. (2006): Transposiciones. Sobre la ética nómada, Barcelona, Gedisa.

Calle, A. (coord) (2011): Democracia Radical, Barcelona, Icaria.

CArrasco, C. (2005): "La economía feminista: una apuesta por otra economía”, en Ma Jesús Vara (coord.), Estudios sobre género y economía, Madrid, Akal.

Castells, M. (1998): Los movimientos sociales urbanos, Madrid, Siglo XXI.

Chambers, R. (1997): “Diagnóstico Rural Participativo: pasado, presente y futuro”, Rev. Bosques, Árboles y Comunidades Rurales, 15-16, pp. 4-9 
CIMAS (2009): Manual Metodologías Participativas. Disponible en web:

$<$ http:/www.redcimas.org/wordpress/wp-content/uploads/2012/09/manual_2010.pdf $>$ [Consulta: 2 de mayo de 2015]

Debord, G. (1976): La sociedad del espectáculo, Madrid, Castellote.

Deleuze, G. y F. Guattari (1988): Mil Mesetas, Valencia, Pre-Textos.

Elías, N. (1982): Sociología fundamental, Barcelona, Gedisa.

ElíAs, N. (1994): Conocimiento y poder, Madrid, La Piqueta.

Fals Borda, O. y C.R. Brandao (1986): Investigación participativa, Montevideo, Instituto del Hombre.

Foucault, M. (1980): Microfísica del poder, Madrid, La Piqueta.

FreIRE, P. (1970): Pedagogía del oprimido, Madrid, Siglo XXI.

Galcerán, M. (2009): Deseo (y) libertad, Madrid, Traficantes de Sueños.

Galtung, J. (1984): Hay alternativas, Madrid, Tecnos.

Galtung, J. (2004): Transcender y transformar, México, Ed. Quimera.

Guattari, F. (1976): Psicoanálisis y transversalidad, Buenos Aires, Siglo XXI.

Haraway, D. (1995): Manifiesto para ciborgs, Valencia, Episteme.

Henderson, H. (1989): "Una guía para montar el tigre del cambio" en Lovelock et al., Gaia, Implicaciones de la nueva biología, Barcelona, Kairós.

Holoway, J. (2011) Agrietar el capitalismo, Barcelona, El Viejo Topo.

IBÁÑez, J. (1994): Por una sociología de la vida cotidiana, Madrid, Siglo XXI.

JAMESON, F. (2004): Una modernidad singular, Barcelona, Gedisa.

Johnson, S. (2003): Sistemas Emergentes, Turner, Madrid. Fondo Cultura Económica.

Keller, E.F. (1994): "Las paradojas de la subjetividad científica", VV.AA. Nuevos paradigmas, cultura y subjetividad, Buenos Aires, Paidós.

LACLAU, E. (2005): La razón populista, Buenos Aires, Fondo de Cultura Económica.

Lapassade, G. (1980): Socioanálisis y potencial humano, Barcelona, Gedisa.

Lourau, R. (1975): El análisis institucional, Buenos Aires, Amorrortu.

Máız, R. (2010): Prólogo a Tilly. Democracia, Madrid, Akal.

Maturana, H. (1995): La realidad, ¿objetiva o construida? Barcelona, Anthropos.

Melucci A. (1994) “¿Qué hay de nuevo en los movimientos sociales?” en E. Laraña y J. Gusfield, Los nuevos movimientos sociales, Madrid, C.I.S., pp.119-150

NARedo, J.M. (2009): Luces en el laberinto, Madrid, La Catarata.

Negri, A. y M. Hart (2005): Multitud, Barcelona, Debolsillo. 
Pinto, R. y T. R. Villasante (2011): La democracia en marcha. Kerala, Barcelona, El Viejo Topo.

Polanyi, K. (2004): La gran transformación, México, Fondo de Cultura Económica.

Ostron, E. (2011): El gobierno de los bienes comunes, México, Fondo de Cultura Económica.

Rancière, J. (1995): La mésentente. Politique et philosophie, Paris, Galilee.

Riechmann, J. (coord.) (2008): ¿En qué estamos fallando? Cambio social para ecologizar el mundo, Icaria, Barcelona.

RoBerts P. (2004): El fin del petróleo, Barcelona, Ediciones B.

R. Villasante, T. (2014): Redes de vida desbordantes. Fundamentos para el cambio desde la vida cotidiana, La Catarata, Madrid.

R. Villasante, T. (2006): Desbordes Creativos. Estilos y estrategias para la transformación social, Madrid, La Catarata.

R. Villasante T. et al. (1989): Retrato de chabolista con piso, Madrid, IVIMA-Alfoz.

R. Villasante T. et al. (1994): Las ciudades hablan, Caracas, Nueva Sociedad.

SACRISTÁn, M. (1987): Pacifismo, ecología y política alternativa, Barcelona, Icaria.

SANTos, B.S. (2005): El milenio huérfano, Madrid-Bogotá, Trotta/ILSA.

SANTos, B.S. (2010): Para descolonizar occidente, Buenos Aires, Prometeo. CLACSO.

SchweickARt, D. (1997): Más allá del capitalismo, Barcelona, Cristianisme i Justicia.

Shiva, V. (2006): Manifiesto por una democracia de la tierra, Barcelona, Paidós.

Situacionistas (1977): La creación abierta y sus enemigos, Madrid, La Piqueta.

Stiglitz, J.E. (2010): Caída libre, Madrid, Taurus.

SubIRATS, J. (2011): Otra Sociedad ¿otra politica?, Barcelona, Icaria.

TARrow, S. (2004): El poder en movimiento, Madrid, Editorial Alianza.

Tilly, C. (2010): Democracia., Madrid, Akal.

Touraine, A. (1996): Crítica de la Modernidad, Madrid, Ediciones Temas de Hoy.

VIRnO, P. (2003): Gramática de la multitud, Madrid, Traficantes de Sueños.

Vygotski L.S. (1995): Pensamiento y lenguaje, Barcelona, Paidós.

WALlERSTEIn, I. (1997): El futuro de la civilización capitalista, Barcelona, Icaria.

Wolf, M. et al. (1980-1990): Antropología social de las sociedades complejas, Madrid, Alianza Editorial. 